The main table gives the sines, cosines, tangents and cotangents from $0^{\circ}$ to $45^{\circ}$ at intervals of $10^{\prime \prime}$. This of course covers the quadrant conveniently. First differences are provided, and the proportional parts of the differences on a page are given in a margin to the table on that page. Auxiliary tables provide the cotangent for the first three degrees for every second, and the sines and tangents for the first degree at intervals of $10^{\prime \prime}$, as in the main table, but in this case six significant figures are given, irrespective of the number of zeros following the decimal point.

Dr. Comrie has supplied a list of eight errors, not all serious, and this has been inserted; so short a list from so severe a critic indicates a high standard of reliability.

The tables are convenient for use. Aesthetically they fall short of elegance by what seems to me to be too frequent a use of "rules", giving the page a crowded, jig-saw appearance ; but this will not be considered a fault by all table-users, and matters little since the fount is of clear, old-style figures.

T. A. A. B.

\title{
CORRESPONDENCE.
}

To the Editor of the Mathematical Gazette.

Dear Sir,-A personal reference by Professor G. H. Livens, on p. 10 of the February Gazette affords me an opportunity of paying a tribute to the late Mr. William Welsh of Jesus College; an opportunity which I cannot resist. Mr. Welsh was a very great teacher, and $I$ have always considered myself fortunate to have been one of his pupils. He succeeded Mr. William Walton (eighth wrangler, 1836) as lecturer at Magdalene, in my first term of residence. As we were not then combined with any other College for lectures, he had the difficult task of covering the schedule for the tripos (the old Part I) by giving the men of each year three lectures weekly, each lecture lasting only 45 minutes. His method, which worked well with a small class, was to sit at a table surrounded by his class and write out his lecture (using no notes) in an easily legible hand, at the same time dictating what he wrote, and at the end giving what he had written to one of the class. Though he covered a vast amount of ground, there was not time for everything; and I have no doubt that Professor Livens got more from him at Jesus College, some twenty years later, including the interesting application of the method. of energy to problems of changing mass, which I had not seen until I read the February Gazette.

Yours faithfully, A. S. RAMSEY.

\section{THE INTEGRAL DEFINITION OF THE LOGARITHM.}

To the Editor of the Mathematical Gazette.

Dear Mr. EdfTor,-Will you allow us to comment on Mr. Tuckey's note in.the Gazette of February, 1945?

No doubt it is true that Hardy's Pure Mathematics (1st edition, 1908) has been a strong influence in favour of the integral definition of the natural logarithm. But Prof. Hardy would be the last to claim either priority or a monopoly in this matter. T. J. I'A. Bromwich, in the preface to his Infinite Series (1907), writes: "It will be noticed that from Art. 11 onwards free use is made of the equation $\frac{d}{d x} \log x=\frac{1}{x}$, although the limit of $\left(1+\frac{1}{n}\right)^{n}$ from 